Western University Scholarship@Western

Centre for the Study of International Economic

Centre for the Study of International Economic

Relations Working Papers

Relations

1984

\title{
On Optimal Currency Substitution Policy and Public Finance
}

Zvi Hercowitz

Efraim Sadka

Follow this and additional works at: https://ir.lib.uwo.ca/economicscsier_wp

Part of the Economics Commons

Citation of this paper:

Hercowitz, Zvi, Efraim Sadka. "On Optimal Currency Substitution Policy and Public Finance." Centre for the Study of International Economic Relations Working Papers, 8436C. London, ON: Department of Economics, University of Western Ontario (1984). 
CENTRE FOR THE STUDY OF INTERNATIONAL ECONOMIC RELATIONS

WORKING PAPER NO. $8436 \mathrm{C}$

ON OPTIMAL CURRENCY SUBSTITUTION POLICY

AND PUBLIC FINANCE

Zvi Hercowitz

and

Efraim Sadka

This paper contains preliminary findings from research work still in progress and should not be quoted without prior approval of the author.

DEPARTMENT OF ECONOMICS THE UNIVERSITY OF WESTERN ONTARIO LONDON, CANADA N6A 5 C 2
Department of Economizs Library

SEP 191984

University of Western Ontario 
ON OPTIMAL CURRENCY SUBSTITUTION POLICY

AND PUBLIC FINANCE ${ }^{\dagger}$ (1)

\author{
by \\ Zvi Hercowitz* and Efraim Sadka **
}

Revised, September 1984

$\dagger_{\text {We wish to thank our colleagues Eitan Berglas and Allan Drazen }}$ with whom we had some useful conversations.

* Tel-Aviv University, and the University of Western Ontario.

** Te1-Aviv University.

Financial support from the Horowitz Institute for Developing Countries, Te1-Aviv University, is gratefully acknowledged.

Depertment of Ecoromics Library

SEP 191984

University of Western Ontario 


\section{Introduction}

One of the means of raising revenue available to a government is the inflation tax on domestic money balances. The demand for these balances and the revenue from inflation depend, among other things, on the tax rate itself and on the degree of substitutability between domestic money and alternative assets, which are referred to in the paper as foreign exchange. (However, the discussion can be interpreted as involving money substitutes in general).

The approach adopted in the paper is the following. The physical or technological differences between the two monies are only with respect to characteristics such as the color or the size of the bills, which cannot explain less-than-perfect substitutability. It is the domestic government that may create imperfect substitution by imposing barriers or regulations on the use of foreign exchange. Only by these means can the government tax domestic money at a rate nigher than the inflation rates in other countries. Given this link between restrictions on foreign exchange and the revenue from inflation, there is room for determining the socially optimal severity of these restrictions.

Phelps (1973) and later Siegel (1978), Helpman and Sadka (1979) and Drazen (1979) studied the optimal determination of the inflation tax from a public finance point of view. In this framework, where all taxes are distortionary and there is an exogenous revenue to be collected, the inflation tax is determined along with the other taxes so as to minimize the total deadweight losses from taxation. A common feature of the aforementioned works is the assumption of an exogenous degree of substitutability between domestic money and alternative assets. Using a similar optimal taxation approach, this paper extends this literature by assuming an endogenous 
substitutability between domestic money and alternative assets and focusing on the restrictions on money substitutes as a policy variable.

The discussion here is also related to Fischer's (1982) in which he addressed the consequences for public finance and welfare, of using a foreign currency instead of a domestic one. The present framework pursues these considerations by treating the two extremes that Fischer considers as the possible corner solutions of a problem in which the two assets may in principle coexist. The issue addressed here is also related, in spirit, to Bryant and Wallace's (1980) discussion of restrictions on the denomination size of money substitutes.

To study the effects of the restrictions on money substitutes at the micro level, we use here a framework in which the demand for monies is generated from inventory theoretic considerations, as in Baumol (1952), Tobin (1956), Barro (1970), Feige and Parkin (1971), Grossman and Policano (1975), and more recently, Jovanovic (1982). 1 There is a legal restriction that only domestic money can be used in transactions. Also, the cost of converting domestic to foreign money and vice versa involves a lump-sum cost. However, this cost is not given by nature, but imposed by government regulations. Hence, there is an attempt here to explain endogenously the size of the financial transaction costs.

From the private point of view, the critical difference between domestic and foreign currency is that the real value of the former depreciates at the rate of inflation while the second is assumed to maintain its real value. Since there is no natural cost of converting foreign exchange to domestic money, if no man-made restrictions on such conversions are imposed, then, with any positive inflation rate, the individuals would hold only foreign exchange and convert it to domestic money just before transacting. This would 
practically eliminate the demand for domestic money and make the foreign exchange the medium of exchange. In this case the government would have no revenue from inflation. However, regulation can prevent this from happening. For instance, imagine the government requiring all these transactions to be carried out through commercial banks, involving nontrivial waste of real resources in the form of paper work, waiting time and use of physical capital (the case of Israel, which motivated this paper, is a good example). Clearly, a preferred way to impose this cost would be to levy a tax on foreign exchange transactions. However, we prefer to address a more realistic problem, in which for some reason or another (perhaps, prohibitive collection costs) such a tax is not used.

The paper is organized as follows. Section II presents the analytical framework. The behavior of the representative individual and firm is analyzed in part (a). Part (b) addresses the general equilibrium and the public finance considerations. To obtain a closed form solution for the individual's decision variables we adopt in Section III a specific utility function. In Section IV we derive the results about optimal public finance and foreign exchange restrictions under a general utility function. Section $V$ contains concluding remarks.

II. The Model: A General Analytical Framework

a. The Private Sector

Consider a competitive economy consisting of a continuum of identical, infinitely lived individuals who consume an aggregate nonstorable consumption good $(c)$, and provide labor services $(L)$. There is also a continuum of identical firms producing under constant returns to scale: a unit of labor produces $\bar{w}$ units of consumption. Therefore, the competitive nominal wage rate $w(t)$ will be equal to $\bar{w}(t)$, where $p(t)$ is the price of the aggregate good. 
The individuals can hold two financial assets. One is a fiat money issued by the government. This is a nominal asset whose real value depreciates with inflation. The other asset has a fixed real value but bears no real interest. This could be, for instance, a currency of a stable-price foreign country, a foreign exchange denominated bank deposit, an indexed bond (bearing no real interest), etc. The two assets serve as stores of value but only the first one (domestic money) can be used as a legal medium of exchange. The second one, which cannot be used as a medium of exchange is referred to from now on as foreign exchange.

Our analysis is confined to a steady state. The representative individual receives $h$ is salary once every $T$ units of time in domestic money. The length $T$ of this period is considered exogenously given by institutional arrangements. 2 Also, we assume no discounting of utility over time. Therefore, all these payment periods are identical and hence it suffices to analyze what happens within one such period, say the period starting at time zero and ending at time $T$.

The objective of the individual is to maximize utility $U(c(\cdot), L(\cdot))$ from the streams of consumption, $c(\cdot)$, and labor services, $L(\cdot)$, over the period $[0, T]$. The function $U$ has the form

$$
U(c(\cdot), L(\cdot))=\int_{0}^{T} u(c(t), L(t)) d t,
$$

where $u$ is interpreted as the instantaneous utility function $\left(u_{1}>0\right.$ and $\left.u_{2}<0\right)$. Notice that the individual will in general choose $c(\cdot)$ and $L(\cdot)$ which vary over time. This makes the model extremely difficult to deal with without adding any significant insight into the nature of the 
problem at hand. 3 For this reason, we simplify the optimization problem by constraining $c(\cdot)$ and $L(\cdot)$ to be constant over time. ${ }^{4}$ Then the objective of the individual becomes that of maximizing $u(c, L)$.

We define the beginning of the payment period (henceforth T-period) as the date in which the individual receives his salary. Given the steady state assumption, it does not matter whether this compensation corresponds to the labor services supplied during the preceding T-period or for those to be supplied during the T-period just started. The nominal after-tax salary is

$$
(1-\beta) w(0) \int_{0}^{T} L(t) d t=(1-\beta) \bar{w} L T,
$$

where $B$ is a proportional income-tax rate and $p(0)$ is normalized to unity. If the individual does not perform any financial transaction at $t=0,(2)$ will remain his stock of domestic money. However, he can also convert part or all of it into foreign exchange. In what follows we analyze the simultaneous determination of the optimal portfolio and labor-consumption choice.

The type of government regulation of foreign exchange described in the introduction is modeled as follows. Each conversion of domestic money to foreign exchange and vice versa involves the cost of $b$ units of the aggregate good. The size of $b$ is determined by the government, but for the individual it is given. Because of this cost, conversions will not be performed continuously. Denote thus the time lapse between two of these transactions by $\tau$. This means that an individual makes $T / \tau$ such conversions during a T-period. We abstract from the difficulty that arises from $T / \tau$ not being in general an integer. 
Let us now examine what happens within a $\tau$-period, defined as the time lapse between two conversions. Since all these periods will be identical at the individual's optimum, consider a $\tau$-period starting at 0 and ending at $\tau$. Given the assumption that consumption is nonstorable, consumption at each $t$ must be purchased at the same $t$. The total nominal cost of these purchases in domestic money is $c \int_{0}^{\tau} p(t) d t$. Therefore this amount of domestic money has to be held at time 0 . For the sake of simplicity, and denoting the instantaneous inflation rate by $\pi$, the price level $p(t)$ is linearly approximated within a t-period by $p(t) \sim 1+$ it $\quad$ (instead of $p(t)=e^{I t}$, recalling that $p(0)$ was normalized to unity). 5 Therefore, the individual needs the amount

$$
\text { c. } \int p(t) d t \stackrel{\sim}{=} c \tau(1+\pi \tau / 2)
$$$$
0
$$

of domestic money at time 0 . Since by the very definition of a t-period one financial transaction is made in each $\tau$-period, the individual also incurs a real cost of b. Recall from (2) that the salary received at time 0

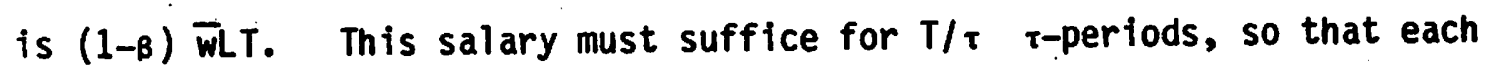
$\tau$-period is allocated a real amount of $(1-\beta) \bar{W} L T /(T / \tau)=(1-\beta) \bar{W} L \tau$. Thus, the individual budget constraint is

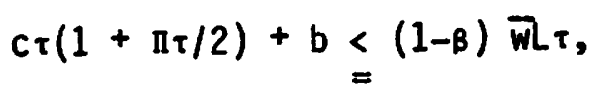

which, upon division by $\tau$, becomes 


$$
c(1+I \tau / 2)+b / \tau \leqq(1-\beta) \overline{W L} .
$$

Equation (3) has a simple interpretation. It implies that the real cost of $c$ to the individual (namely, $1+\mathbb{I} \tau / 2$ ) is greater than the (social) production cost which is one, whenever $I$ and $\tau$ are positive. This difference in the cost is due to the depreciation of the domestic money. balances that the individual chooses to hold between a financial transaction and the purchases of c. The average length of time between these two kinds of transactions is ז/2. Since the instantaneous inflation rate is $\pi$, the individual loses on average $\pi \tau / 2$ per unit of consumption. An alternative, more standard interpretation of the price of $c$ can be obtained by considering the average real balances of domestic money that the individual holds. These average real balances are approximated by $(c \tau+0) / 2=c \tau / 2$. Since $n$ is the instantaneous depreciation rate of domestic money, the expression $\pi \mathrm{c} / 2$ represents the corresponding inflation tax per unit of time.

Notice that in this framework the price of $c$ is determined by the individual: by choosing a lower $\tau$ he can bring down the price closer to the social cost which is unity; but in this way the frequency of the financial transactions increases, implying nigher transaction costs per unit of time $(b / \tau)$. By choosing the optimal $\tau$, the individual simultaneously chooses the privately optimal price of $c$ and the financial transaction costs per unit of time. The individual's problem is thus to choose $\tau$, along with $c$ and $L$, so as to maximize $u(c, L)$, subject to the budget constraint $(3)$. This yields an indirect utility function $v(\beta, \pi, b)$, a consumption demand function $c(\beta, \pi, b)$, a labor supply function $L(B, \Pi, b)$, and an optimal length of the $\tau$-period, 
$\tau(\beta, \Pi, b)$. These functions imply the individual's demand for real balances of domestic money, which on average during a t-period is

$$
C(\beta, \pi, b) \tau(\beta, \Pi, b) / 2
$$

As already mentioned, there is a continuum number ( $\mathrm{nT}$ ) of individuals. The payment day of salaries is uniformly distributed across individuals, so that at each $t$ there is an equal number $(n)$ of individuals receiving their salaries.

Consider now a representative firm. We assume that the payment day of salaries is uniformly distributed across the workers of each firm, so that at each $t$, there is an equal number of the firm's workers who receive their salaries at this t. We also assume that the buyers are uniformly distributed across firms at each $t$. Therefore, the inflow and outflow of money of the firm are constant over time and, by the constant-returns-to-scale assumption, they are equal to each other: the gross wage bill is equal to the sales revenue. This setup of the model has the important implication that the firm's demand for money is zero. It enables us to concentrate our attention on the household demand for money which comprises the total demand for money in this economy.

\section{b. General Equilibrium and Public Finance}

Consider now the government budget constraint. It demands a fixed amount of real resources equivalent to $G$ units of the consumption good per person per unit of time. This expenditure is financed by the revenue from wage taxation and by printing new money. At each $t$, there are $n$ individuals 
receiving each a gross nominal salary of $w(t) T L$. Thus, the government's tax revenues at $t$ are $B n w(t) T L$ which amounts. to $B w(t) L$ per

capita. Denoting the nominal per capita supply of money at $t$ by $M(t)$, then the government's per capita revenue from printing money at $t$ is $\dot{M}(t)$, where a dot stands for differentiation with respect to time. Thus, the government faces the following budget constraint at each $t$ :

$$
p(t) G \leq B W(t) L+\dot{M}(t)
$$

Dividing through by $p(t)$ yields (recalling that $w(t)=\bar{w} p(t)$ ):

$$
G \stackrel{B}{=} \overline{W L}+\dot{M}(t) / p(t) \text {. }
$$

Since at a steady-state the real per-capita supply of money $m \equiv M(t) / p(t)$ is constant, it follows that $\dot{M}(t) / p(t)=$ Im and hence the government budget constraint at each $t$ can be written as

$$
G \leq B \overline{W L}+\mathbf{I m}
$$

The resource constraint of the economy (or, equivalently, the commodity market equilibrium condition) is given in per-capita terms by

$$
c(\beta, \pi, b)+G+b / \tau(\beta, \pi, b) \leq \overline{W L}(\beta, \Pi, b) .
$$

The term $b / \tau$ on the LHS of (5) represents the real cost of the foreign exchange restrictions. Since there are $\mathrm{nT}$ individuals, each making one transaction in foreign exchange every $\tau$ units of time, it follows that there are $n T / \tau$ individuals making such a transaction at each point of time. The total cost per unit of time is $b n T / \tau$ and the per-capita cost is thus $b / \tau$. 
Consider now the equilibrium condition for the demand and supply of domestic money. The per-capita real supply was denoted by $m$. As discussed. above, the individual holds an average balance of $c \tau / 2$. This average is for a given individual over a $\tau$-period. But notice that in our model, averaging over time for a given individual is the same as averaging over individuals at a given point in time. Hence, $c \tau / 2$ is also the per-capita real balance of domestic money. Thus, the equilibrium condition for domestic money is

$$
m=C(B, \pi, b) \tau(B, \pi, b) / 2 \text {. }
$$

Finally, notice that when the individual determines $c, \tau$ and $L$, he implicitly decides on his holding of foreign exchange. By the same reasoning used above, the average holding of foreign exchange by an individual over time equals the average across individuals at each point in time. Hence, the per-capita holdings of foreign exchange is constant over time, and is equal, in the steady state, to the per-capita stock of foreign exchange that was accumulated in the indefinite past. Thus, the foreign exchange market is in equilibrium. Put differently, the real rate of exchange was determined once and for all in the indefinite past so as to equilibrate the market for forefgn exchange.

The government's objective is to maximize the individual's welfare. It determines the tax rate, the money growth rate and the foreign exchange regulations. It has to abide by its budget constraint and to take into account the individual behavior, as described above. Formally, the government chooses $B, \mathbb{n}, b$ and $m$ so as to maximize the individual's indirect utility function $v(\beta, \pi, b)$, subject to its budget constraint (4) and the 


$$
u(c, L)=c^{\alpha}(H-L)^{1-\alpha}, \quad 0<\alpha<1,
$$

where $H$ is the total available leisure per unit of time. With this utility function we are able to obtain explicit solutions for the individual's choice of $c, L$ and $\tau$ as functions of the government's policy variables $B$, II and $b$. The budget constraint (3) can be rewritten as

$$
c(1+\pi \tau / 2)+(1-\beta) \bar{w}(H-L) \leqq(1-\beta) \bar{w} H-b / \tau .
$$

Then, for a given $\tau$, we can interpret $(1-\beta) \bar{w} H-b / \tau$ as the individual's net full-income, and $1+\pi \tau / 2$ and $(1-\beta) \bar{w}$ as the prices of the commodities $c$ and $(H-L)$, respectively. Thus, for a given $\tau$, the choices of $c$ and $(H-L)$ are given by the standard Cobb-Douglas demand expressions:

$$
c=\frac{\alpha[(1-\beta) \overline{w H}-b / \tau]}{1+\pi \tau / 2}
$$

$$
H-L=\frac{(1-\alpha)[(1-\beta) \bar{w}-b / \tau]}{(1-\beta) \bar{w}}=(1-\alpha)\left[H-\frac{b}{(1-\beta) \bar{w}_{\tau}}\right] \text {. }
$$

Substituting (10) into the utility function (9) yields the expression

$$
\alpha^{\alpha}(1-\alpha)^{1-\alpha}[1+\pi \tau / 2]^{-\alpha}[(1-\beta) \bar{w}]^{-(1-\alpha)}[(1-\beta) \bar{w}-b / \tau],
$$

in which $\tau$ is the only remaining choice variable. By maximizing now (11) with respect to $\tau$, we find the individual's choice of the financial transactions period:

$$
\text { (12) } \tau(\beta, \pi, b)=\frac{(1+\alpha) b}{2 a(1-\beta) \overline{W H}}+\left[\frac{(1+\alpha)^{2} b^{2}}{4 \alpha^{2}(1-\beta)^{2} \bar{w}^{2} H^{2}}+\frac{2 b}{a \pi(1-\beta) \overline{W H}}\right]^{\frac{1}{2}} \text {. }
$$


equilibrium conditions (5) and (6). By Walras Law, one of the latter two equilibrium conditions is redundant. The reader can easily verify that, for instance, (4), (6) and the individual budget constraint (3) imply (5), so that (5) may be deleted. 6 Also, m can be substituted from (6) into (4). Thus, the government's optimization problem is reduced to: choose $B$, II and b so as to solve the problem

$$
\max v(\beta, \pi, b)
$$

subject to:

$$
G \stackrel{s}{=} B \overline{W L}(\beta, \pi, b)+\pi C(\beta, \pi, b) \tau(\beta, \pi, b) / 2
$$

Instead of proceeding to the general solution of this optimization problem, we first adopt in the next section a specific form of the utility function to study the individual response to the government's policy variables ( $B, I$ and $b)$; and use numerical simulation methods in section IV to obtain some insight into the government's optimization problem. These numerical results lead us to conjecture some general analytical conclusions about the desirability of various government financing tools. Finally, we prove these conjectures.

\section{Individual Behavior: A Specific Utility Function}

In this section we adopt a Cobb-Douglas utility function in order to be able to study the individual choice of $c, L$ and $\tau$. Specifically, consider the utility function 


$$
u(c, L)=c^{\alpha}(H-L)^{1-\alpha}, \quad 0<\alpha<1,
$$

where $H$ is the total available leisure per unit of time. With this utility function we are able to obtain explicit solutions for the individual's choice of $c, L$ and $\tau$ as functions of the government's policy variables $B, \pi$ and $b$. The budget constraint (3) can be rewritten as

$$
c(1+\pi \tau / 2)+(1-\beta) \bar{w}(H-L) \leqq(1-\beta) \bar{w} H-b / \tau .
$$

Then, for a given $\tau$, we can interpret $(1-\beta) \bar{w} H-b / \tau$ as the individual's net full-income, and $1+\pi \tau / 2$ and $(1-\beta) \bar{w}$ as the prices of the commodities $c$ and $(H-L)$, respectively. Thus, for a given $\tau$, the choices of $c$ and $(H-L)$ are given by the standard Cobb-Douglas demand expressions:

$$
c=\frac{\alpha[(1-\beta) \overline{w H}-b / \tau]}{1+\pi \tau / 2}
$$

$$
H-L=\frac{(1-\alpha)[(1-\beta) \overline{W H}-b / \tau]}{(1-\beta) \bar{w}}=(1-\alpha)\left[H-\frac{b}{(1-\beta) \bar{w} \tau}\right] .
$$

Substituting (10) into the utility function (9) yields the expression

$$
\alpha^{\alpha}(1-\alpha)^{1-\alpha}[1+\Pi \tau / 2]^{-\alpha}[(1-\beta) \bar{w}]^{-(1-\alpha)}[(1-\beta) \bar{w}-b / \tau]
$$

in which $t$ is the only remaining choice variable. By maximizing now (11) with respect to $\tau$, we find the individual's choice of the financial transactions period:

$$
\text { (12) } \tau(\beta, \pi, b)=\frac{(1+a) b}{2 a(1-\beta) \bar{w} H}+\left[\frac{(1+a)^{2} b^{2}}{4 a^{2}(1-\beta)^{2} \bar{w}^{2} H^{2}}+\frac{2 b}{a \Pi(1-\beta) \bar{w}}\right]^{\frac{1}{2}} \text {. }
$$


The choices of $c$ and $L$, namely the functions $c(\beta, \pi, b)$ and $L(\beta, \pi, b)$, respectively, are then obtained by substituting the expression for $\tau$ in (12) into (10).

From (12) it is straightforward to obtain standard results in the inventory-theoretic approach to the demand for money that:

$$
\frac{\partial \tau}{\partial \beta}>0, \quad \frac{\partial \tau}{\partial I}<0 \quad \text { and } \quad \frac{\partial \tau}{\partial b}>0
$$

Thus, a rise in the net wage (i.e. a fall in B) lowers $\tau$. Intuitively, as the individual has a higher net income, the stream of consumption rises and with it the need to hold more domestic money; therefore, the individual's exposure to the inflation tax increases which induces him to accelerate the frequency of conversion of foreign exchange. ${ }^{7}$ Similarly, a rise in II also lowers the length of the holding time of domestic money, while an increase in the cost of converting foreign exchange (b) increases it.

By multiplying (12) by $I$, we can see that $a(n \tau) / \partial \Pi>0$. Thus, it follows from (10) that $\partial c / \partial \mathbb{I}<0$ (recall from (13) that $\partial \tau / \partial \Pi<0)$. That is, a higher inflation reduces consumption. Also, by dividing (12) by b, we can see that $\partial(\tau / b) / \partial b<0$, so that $\partial(b / \tau) / \partial b>0$. Hence, $\partial c / \partial b<0$, i.e. an increase in the financial transaction cost lowers consumption. The effect of a change in the tax rate $\beta$ on $c$ is indeterminate.

Since $\partial \tau / \partial \pi<0$, it follows from (10) that $a L / \partial \pi>0$, 1.e. a nigher inflation rate induces more labor supply. By multiplying (12) by 1-B, we can see that $\partial[\tau(1-\beta)] / \partial(1-\beta)>0$. Thus, $\partial L / \partial(1-\beta)<0$. This is quite a surprising result, as it implies a backward-bending labor supply curve. We have already seen that $\partial(b / \tau) / \partial b>0$ and hence it follows from (12) that $a L / a b>0$ : a higher financial transaction cost induces more labor supply. 
We also observe that all the three policy variables ( $\beta, \pi$ and $b$ ) reduce the individual utility. This follows from the envelope theorem which implies that

$$
\frac{\partial V}{\partial \beta}=-\theta \overline{W L}, \quad \frac{\partial V}{\partial \pi}=-\theta C \tau / 2 \text { and } \frac{\partial V}{\partial b}=-\frac{\theta}{\tau} \text {, }
$$

where $\theta>0$ is the marginal utility of income (i.e. the Lagrangian multiplier associated with the individual's constrained optimization problem of maximizing $u(C, L)$, subject to the budget constraint (3)).

Finally, the length of the t-period depends on the structure of preferences over the real variables - consumption and leisure. This is seen immediately from (12) where the RHS depends on a which is a parameter in the utility function; furthermore, the formula itself for $\tau$ will change if we employ a utility function different from the Cobb-Douglas.

IV. Optimal Financing of the Budget: The Desirability of Inflation

The numerical simulation of the government optimization problem (7)-(8) is performed using the utility function (9). For this purpose, we assume that $H$ is equal to 24 hours per day and that $a=1 / 3$ which means that roughly $(1-1 / 3) \times 24=16$ hours per day are consumed as leisure time. The value of $\bar{w}$ employed is approximately the average wage in Israel during the fiscal year 1980/81, IS 25 per hour ( I dollar = IS 6). Among other things, we wanted to see how the various government control variables - $B$, II and b vary with the size of budget - G. For this reason, we considered various levels of $G$ ranging from IS 40 to IS 100 per person per day, i.e. from about roughly 20 percent to 50 percent of the national income. 
The numerical results are depicted in Table 1. This table shows that

TABLE 1

$\begin{array}{rrrrrr}\underline{G} & \underline{C} & \underline{L} & \underline{B} & \underline{I} & \underline{b} \\ 40 & 160 & 8 & 0.2 & 0 & 0 \\ 60 & 140 & 8 & 0.3 & 0 & 0 \\ 80 & 120 & 8 & 0.4 & 0 & 0 \\ 100 & 100 & 8 & 0.5 & 0 & 0\end{array}$

inflationary finance is never optimal. We always get $b=\mathbb{I}=0$ and wage taxation as the only source of revenues. As the size of the government's budget $(G)$ increases, B rises, $L$ stays constant and $c$ falls a shekel for a shekel of $G$. This means that the resources needed for the government are provided by lowering consumption rather than by increasing work effort. 8 Notice that with $\pi=b=0, \tau$ is indeterminate and irrelevant $-\tau$ enters the equations of the model, (3) and (8), only through the product It or the quotient $b / \tau$ which are both zero. When $\pi=b=0$, both the private sector and the government are indifferent between the use of domestic or foreign currency. The government does not tax nor regulate the transactions sector of the economy. The budget is satisfied by taxing labor only. This solution can 
be seen as corresponding to either the adoption of a stable-valued foreign currency for domestic use - the dollarization scheme considered by the Israeli treasury in 1983 -- or to a fixed exchange rate against such a currency, coupled with a completely passive monetary policy.

The question naturally arises whether this result about the inefficiency of inflationary finance, which we observed for the Cobb-Douglas utility function and certain parameter values, is a more general result. The answer is in the affirmative under quite reasonable assumptions. The feature of the analysis - which seems fairly general - that is primarily responsible for this result is the type of money demand function generated by the model. As indicated by equation (6), money demand is proportional to consumption (in general, it could be some other economic activity variable). This proportionality holds for any transaction frequency and, in particular, for the optimal one. Because of this link, a tax on money holdings amounts to an implicit tax on consumption. 9 This is reflected in the private budget constraint (3), where the term $1+n \tau / 2$ multiplies c. Aside from some wealth effects (see below), the distortionary effects of the inflation tax on the relative price and the revenue collected by the government are the same as those under an appropriate explicit tax rate. However, the inflation tax is accompanied by a waste of resources in transaction costs. This waste directly reduces welfare, but in our second-best world it may have some desirable indirect effect: The loss of income induces more labor supply -- assuming that leisure is a normal good. As the labor supply increases, so do wage tax revenues; this in turn allows the government to lower the wage tax rate and thereby improve welfare. 
However, as we see below, the condition for the indirect effect to dominate is highly implausible and therefore we can rule out inflationary finance under quite weak assumptions.

To formalize this result, let us compare welfare in two situations. One in which there is no inflation $\left(b^{\star}=\Pi^{\star}=0\right)$ and all revenues are raised by a wage tax, i.e. $\beta=\beta^{\star}$, such that $\beta^{\star} \mathbb{W}=G$. The other is an inflationary finance case characterized by $b=\tilde{b}>0, \pi=\tilde{I}>0$ and $B=\bar{\beta}$. Consider first the inflationary finance case. Given $\bar{B}, \tilde{\pi}, \tilde{b}$ and $\tilde{\tau}=\tau(\bar{B}, \tilde{\pi}, \tilde{b})$, the consumer budget constraint can be written as

$$
c(1+\tilde{\pi} \tau / 2)+\tilde{b} / \tilde{\tau} \leq(1-\bar{\beta}) \bar{w} L \text {. }
$$

Putting $\tilde{r} \equiv 1+\tilde{\pi} \tau / 2$, and dividing by $\tilde{r}$, this constraint is transformed to

$$
c \leqq(1-\tilde{\beta}) \omega L-\tilde{b} / \tilde{\tau} \gamma \text {, }
$$

where $1 \tilde{-\beta}=(1-\bar{B}) / \tilde{\gamma}$, and $\tilde{B}$ can be interpreted as the inflation-adjusted tax rate. The consumer welfare is then $v((1-\tilde{\beta}) \bar{w}, \tilde{-b} / \tilde{i} \gamma)$, where $v$ is the standard indirect utility function which depends on the net wage $(1-\bar{B}) \bar{w}$ and the "nonwage income" $-\tilde{b} / \tilde{\tau} r$. By subtracting $\left(3^{\prime}\right)$ from the resource constraint (5), we can write the government's budget constraint (8) as

$$
G+\tilde{b}(\tilde{\gamma}-1) / \tilde{\tau \gamma} \leqq \tilde{B \overline{W L}}
$$

The point to be made from $\left(3^{\prime}\right)$ and $\left(8^{\prime}\right)$ is that the inflationary case can be interpreted as follows: There is a wage tax at the rate $\tilde{B}$ and $a$ lump-sum tax of $\tilde{b} / \tilde{\tau} r$. The proceeds from this lump-sum tax are destroyed, as they do not appear as a source of revenue to the government. Moreover, the government incurs an extra cost of $\tilde{b}(\tilde{r}-1) / \tilde{\tau} r$ (recall that $\tilde{r}>1$ ), equalling the difference between the transaction cost $\tilde{b} / \tilde{\tau}$ and the lump-sum tax $\tilde{b} / \tilde{\tau} r$. 
Consider now the case without inflationary finance, i.e., $b^{*}=\mathbb{I}^{\star}=0$. In this case the individual budget constraint (3) and the government budget constraint (8) can be written as:

$$
c \leq\left(1-\beta^{*}\right) \overline{W L}=\left(1-\beta^{*}\right) \bar{W} L-b^{\star} / \tilde{\tau \gamma} .
$$

In this case - unlike the inflationary finance case - notice that the term $b^{*} \tilde{(\gamma-1) / \tilde{\tau} r}$ is equal to zero, so that the government does not incur any extra cost.

We want then to find when

$$
V\left(\left(1-\beta^{\star}\right) \bar{w},-b^{*} / \tilde{\tau} \tilde{\gamma}\right)>V((1-\tilde{\beta}) \bar{w},-\tilde{b} / \tilde{\tau} \gamma) .
$$

In other words, we ask when an increase in lump-sum taxation from $b * \tilde{\tau r}=0$ to $\tilde{b} / \tilde{\tau r}>0$, coupled with a change in the wage tax rate from $B^{*}$ to $\sim$ B reduces welfare.

To proceed further we have to find the relationship between $b$ and $B$ as implied by the government's budget constraint. For this purpose, write the latter constraint as

$$
G+b \tilde{r}-1) / \tilde{\tau} \tilde{\gamma} \leqq \beta \overline{W L}((1-\beta) \bar{w},-b / \tilde{\tau} \gamma)
$$

and employ total differentiation to get:

$$
\frac{d \beta}{d b}=\frac{\beta \bar{W} L_{2} / \tilde{\tau} \gamma+(\tilde{\gamma}-1) / \tilde{\tau \gamma}}{\bar{w} L-\beta \bar{w}^{2} L_{1}},
$$

where $L_{i}$ is the partial derivative of $L=L((1-\tilde{\beta}) \bar{w},-\tilde{b} \tau / \tilde{\gamma})$ with respect to its $i$ th argument, $i=1,2$. 
Clearly, (14) holds if

$$
\frac{d V}{d b}<0
$$

everywhere between $b=b^{*}$ and $b=\tilde{b}$, when (15) is taken into consideration. Employing Roy's identity, we find that

$$
\frac{d V}{d b}=-V_{1} \bar{w} \frac{d \beta}{d b}-\frac{V_{2}}{\tau \sim}=-V_{2}\left(\bar{w} L \frac{d \beta}{d b}+\frac{1}{\tau \sim}\right),
$$

where $V_{i}$ is the partial derivative of $V$ with respect to its ith argument, $i=1,2$. Since $V_{2}$ is positive, it follows from (17) that (16) holds if:

$$
\bar{w} L \frac{d \beta}{d b}+\frac{1}{\tau \gamma}>0
$$

Substituting (15) into (18) yields

$$
\frac{\beta \bar{w}^{2} L L_{2}+\bar{w} L(\tilde{\gamma}-1)+\bar{w} L-\beta \bar{w}^{2} L_{1}}{\bar{w} L-\beta \bar{w}^{2} L_{1}}>0 .
$$

We assume that $\partial(B \bar{W} L) / \partial \beta=\bar{W} L-B \bar{W}^{2} L_{1}>0$ for all values of $B$ in the relevant range, i.e., we assume that all relevant tax rates correspond to the upward sloping part of the "Laffer curve". (The case in which it is violated is is mentioned below in the concluding section.) Employing the Hicks-Slutsky equation $L_{1}^{c}=L_{1}-L_{2}$, where $L_{1}^{C}$ is the compensated wage derivative of $L,(19)$ becomes:

$$
-\beta \bar{W}^{2} L_{1}^{c}+\tilde{\gamma} \bar{W} L>0
$$

Since $\tilde{r}>1$, it follows that (20) holds if $-\beta \bar{w}^{2} L_{1}^{c}+\bar{w} L 0$. The latter condition can be written in two alternative formulations:

$$
\sigma<(1-\beta) / \beta \text {, }
$$


or

$$
\left(\beta^{-}\right)\left(\beta^{-}\right) L_{1}^{c} / 2<\beta^{-} \mathrm{w} L / 2,
$$

where $\sigma \equiv L_{1}^{c} \bar{w}(1-\beta) / L$ is the compensated wage elasticity of the labor supply. Inequality (21) is a sufficient condition for ruling out inflationary finance. It always holds at low tax rates for then $(1-\beta) / \beta \rightarrow+\infty$. Thus, inflationary finance is never desirable under a "sma11" government. More generally, inflationary finance is not desirable whenever the excess-burden of wage taxation is not extremely high. This can be seen either from (21a) or from (2lb). In (2la), a low compensated elasticity $(\sigma)$ and/or a low marginal tax rate $(\beta)$ are indicators of low excess burden. In (21b), the term $\left(\beta^{-}\right)\left(\beta^{-}\right) L_{1}^{c} / 2$ is approximately the excess-burden (Harberger's triangular) of wage taxation. 10 Thus, (21b) holds whenever the excess-burden does not exceed one-half of the tax revenues.

\section{Concluding Remarks}

The question addressed in this paper is whether it is socially desirable that the government imposes restrictions on foreign exchange in order to make possible the taxation of domestic money by inflation. Under some reasonable assumptions, the answer obtained is negative. Domestic currency should be made a perfect substitute for the stable-valued alternative, or in other words, the socially optimal degree of currency substitution is infinite. As discussed in the previous section, the basic reasoning behind this result is that inflation works as an indirect tax on the economic activity affecting money demand -- consumption, in the present case. A financing scheme that replaces the inflationary tax and the accompanying costs of currency regulation for a higher direct taxation of that activity or a closely related one -- as 
income in the present case -- saves those artificial costs and hence it is likely to be optimal.

In order to put this result in an appropriate perspective, we want to discuss here some additional considerations that can potentially make the case for imperfect currency substitution stronger. Consider a setup in which the demand for monies depends on total private income, but only part of it is generated in activities reported to the income-tax authority. When foreign currency restrictions are in effect, the inflation tax on domestic money works as an indirect tax on total income, while the direct income-tax applies practically to only part of it. Lowering the restrictions on money substitutes -- thereby reducing the inflation tax revenue -- and increasing the explicit income-tax may be undesirable in this setup, because then the unreported activity goes less taxed. This is likely to aggravate the non-optimality of the relative tax burdens of the reported and unreported activities.

Also, the present discussion assumed no tax-collection costs. This assumption is clearly appropriate with respect to the inflation tax because it is collected simply by printing more money under negligible costs. With regard to the income tax, this assumption is more of an approximation. Consider, for example, an underdeveloped type of economy in which the accounting practices and the administrative apparatus necessary to enforce an efficient income taxation are not well developed. In this case the government may face increasing tax collection costs that could generate an interior solution, involving foreign exchange restrictions to allow for inflationary finance. However, it seems to us that this type of consideration may not be important in more developed economies. 
Another case for foreign currency restriction can be made when the assumption that the optimal tax rate $\beta$ * corresponds to the upward sloping part of the Laffer curve is violated. Namely, government spending can be increased beyond the maximum amount of revenue that can be raised by income taxation. Then, if there is no other tax available, the wasteful currency regulation has to be activated in order to permit inflationary taxation. This result was not obtained in Section IV (see Table 1) because under the Cobb-Douglas utility function revenue from the income tax is always increasing -- of course, for rates lower than 100 percent. In this respect, recall that throughout this paper government spending was assumed exogenously given. If $G$ is made endogenous, the marginal benefit from it would be compared with the marginal distortion of taxation. When only inflationary finance can increase total revenue, its heavier welfare cost will make a level of $G$ beyond the maximum revenue from the income-tax less likely to be desirable.

Finally, the simplicity of the results obtained in this paper has to do with the assumption of uniform flows of consumption and leisure. In the more general case, consumption during the transaction period would vary. Under inflation the individual would tend to concentrate consumption purchases after a financial transaction. An additional, intertemporal, distortion of inflation would then be present. For this reason, one can conjecture that in the general case inflationary finance is likely to be even less desirable than under the present case. 


\section{FOOTNOTES}

1. Feige and Parkin (1971) and Jovanovic (1982) also addressed normative issues related to inflation. The fundamental difference between our approach and theirs is that in our model the revenues from printing money (the inflation tax) are used, together with other distortionary sources of revenues to finance government consumption, whereas in theirs the proceeds from inflation are returned to the consumer in a lump-sum. In our opinton, the practical relevance of discussing the optimal inflation rate is questionable when one ignores the government's need to ratse revenues.

2. In principle, the analysis could be extended to incorporate an endogenous payments period, as in Barro (1970). However, for the present purposes we do not see any possible additional insights that would be obtained in such an extension.

3. See also Barro (1970): "... as inflation Intensifies, employees are ... motivated to concentrate expenditures closer to payment times in order to reduce money holdings and incur smaller losses from inflation. However, a preliminary model of this behavior suggests that the general relationship between average money holdings and the rate of inflation is not materially altered by a consideration of this motive."

4. The constancy of $c(\cdot)$ and $L(\cdot)$ may be obtained by assuming that (1) takes the special form

$$
U(c(\cdot), L(\cdot))=u(\min \{c(t) / 0 \leq t \leq T\}, \max \{L(t) / 0 \leq t \leq T\}) .
$$


5. This approximation amounts to calculating a simple inflation rate within a $\tau$-period instead of a compounded rate. Given that realistic values of $\tau$ are relatively small, this approximation, which is a common practice in the inventory-theoretic approach to money demand, seems quite reasonable.

6. Strictly speaking, since the individual budget constraint (3) and the money market equilibrium condition (6) were obtained by some approximations, then Walras Law does not have to hold in general. However, in our case Walras Law does hold because we simply. chose the approximations in (3) and (6) in such a way as to maintain Walras Law. The reader can in a straightforward way verify that Walras Law will, of course, hold when (3) and (6) are replaced by their exact forms, namely

$$
c\left(e^{\Pi \tau}-1\right) / \pi \tau+b / \tau \stackrel{<}{=}(1-\beta) \overline{w L}
$$

and

$$
m=\frac{1}{\tau} c \int_{0}^{\tau}\left(\int e^{\tau} e^{\pi(s-t)} d s\right) d t
$$

respectively.

7. This result hinges upon our assumption that the transaction cost $b$ is not in leisure time and therefore it does not rise with the net wage.

8. Given that $b=\pi=0$, this result follows from the assumption of Cobb-Uouglas preferences which yield a perfectly inelastic labor supply.

9. Notice that we do not have a consumption tax but a wage tax can achieve a similar effect as a consumption tax, and the same one when $b=0$.

10. The approximation is exact when $L_{1}^{c}$ is constant. 
REFERENCES

Barro, R.J. (1970), "Inflation, the Payments Period, and the Demand for Money", Journal of Political Economy, 78, 1228-1263.

Baumol, W.J. (1952), "The Transactions Demand for Cash: An Inventory Theoretic Approach", Quarterly Journal of Economics, 66, 545-66.

Bryant, J. and Wallace, N. (1980), "A Suggestion for Further Simplifying the Theory of Money", Federal Reserve Bank of Minneapolis, Staff Report 62. Drazen, A. (1979), "The Optimal Rate of Inflation Revisited," Journal of Monetary Economics, 5, 231-48.

Feige, E.L. and Parkin, M. (1971), "The Optimal Quantity of Money, Bonds, Commodity Inventories and Capital", American Economic Review, 61, 335-49. Fischer, S. "Seigniorage and the Case for a National Money", (1982) Journal of Political Economy, 90, 295-313.

Grossman, H.I., and Policano, A.J. (1975), "Money Balances, Commodity Inventories, and Inflationary Expectations", Journal of Political Economy, 83, 1093-1112.

Helpman, E. and E.Sadka (1979), "Optimal Financing of the Government's

Budget: Taxes, Bonds, or Money "American Economic Review, 69, 152-60. Jovanovic, B. (1982), "Inflation and Welfare in the Steady State," Journal of Political Economy, 90, 561-577.

Phelps, E.S. (1973), "Inflation in the Theory of Public Finance," Swedish Journal of Economics, $75,67-82$.

Siegel, J. (1978), "Notes on the Optimal Taxation and the Optimal Rate of Inflation," Journal of Monetary Economics, 4, 297-305.

Tobin, J. (1956), "The Interest Elasticity of the Transactions Demand for Cash", Review of Economics and Statistics, 38, 241-47. 


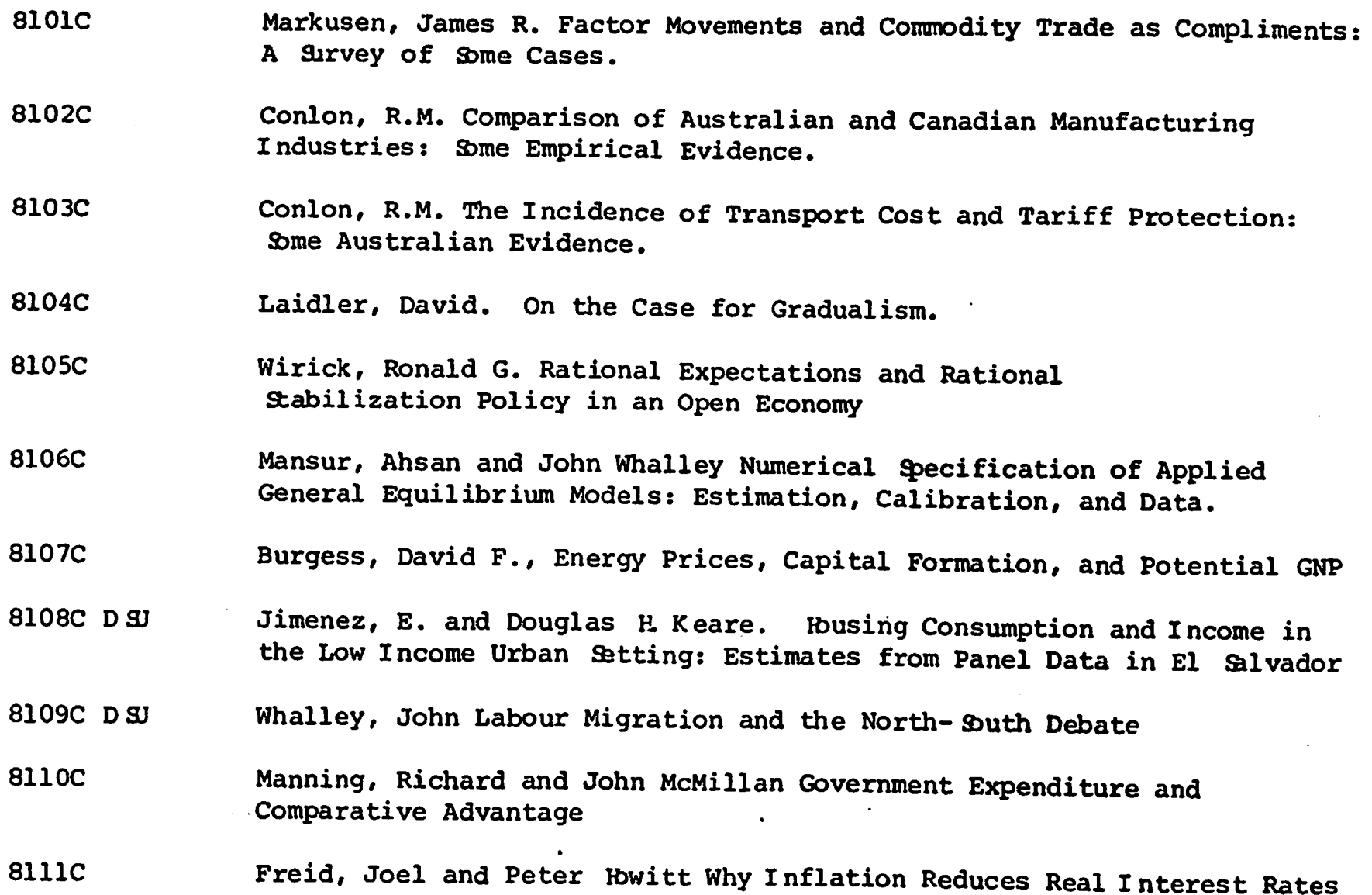

\section{2}

$8201 C$

Manning, Richard and James R. Markusen Dynamic Non- Substitution and Long Run Production Possibilities

$8202 \mathrm{C}$

Feenstra, Robert and Ken Judd Tariffs, Technology Transfer, and Welfare

$8203 C$

$8204 \mathrm{C}$

Ronald $W$. Jones, and Douglas D. Purvis: International Differences in Response to Common External hocks: The Role of Purchasing Power Parity

James A Brander and Barbara J. Spencer: Industrial strategy with Committed Firms

$8205 C$

Whalley. John, The North-South Debate and the Terms of Trade: An Applied General Equilibrium Approach

$8206 C$

$8207 \mathrm{C}$

Roger Betancourt, Christopher Clague, Arvind Panagariya CAPITAL UTIIIZATI ON IN GENERAL EQUIITBRI UM

Mansur, Ahsan $H_{6}$ On the Estimation of Import and Export Demand Elasticities and Elasticity Pessimism.

8208C

Whalley, J. and Randy WIgle PRICE AND QUANTITY RIGIDITIES IN ADJUSTMENT TO TRADE POLICY CHANGES: ALTERNATIVE FORMULATIONS AND INITIAL CALCULATIONS

8209C DSU Jimenez, E. SQUATTING AND COMMUNITY ORGANIZATION IN DEVELOPING COUNTRIES: A CONCEPTUAL FRAMEWORK 
8210C Grossman, G.M. INTERNATIONAL COMPETITION AND THE UNIONIZED SECTOR

8211C Laidler,D. FRIEDMAN AND SCHWARTZ ON MONETARY TRENDS - A REVIEW ARTICLE

8212C Imam, M.H. and Whalley, J. INCIDENCE ANALYSIS OF A SECTOR SPECIFIC MINIMUM WAGE IN A TWO SECTOR HARRIS-TODARO MODEL.

8213C Markusen, J.R. and Melvin, J.R. THE GAINS FROM TRADE THEOREM WITH INCREASING RETURNS TO SCALE. 8214C INDUSTRIAL ORGANIZATION AND THE GENERAL EQUILIBRIUM COSTS OF PROTECTION IN
SMALL OPEN ECONOMIES.

8215C Laidler, D. DID MACROECONOMICS NEED THE RATIONAL EXPECTATIONS REVOLUTION?

8216C Whalley, J. and WIgle, R. ARE DEVELOPED COUNTRY MULTILATERAL TARIFF REDUCTIONS NECESSARILY BENEFICIAL FOR THE U.S.?

8217C Bade, $R$. and Parkin, M. IS STERLING M3 THE RIGHT AGGREGATE?

8218C Kosch, B. FIXED PRICE EQUUILIBRIA IN OPEN ECONOMIES.

\section{3}

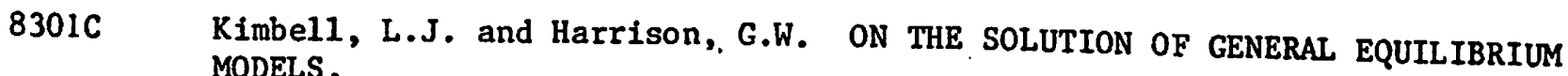

8302C Melvin, J.R. A GENERAL EQUILIBRIUM ANALYSIS OF'.CANADIAN OIL POLICY.

8303C Markusen, J.R. and Svensson, L.E.0. TRADE IN GOODS AND FACTORS WITH INTERNATIONAL DIFFERENCES IN TECHNOLOGY. 8304C Mohammad, S. Whalley, J. RENT SEEKING IN INDIA: ITS COSTS AND POLICY
SIGNIFICANCE.

8305C DSU Jimenez, E. TENURE SECURITY AND URBAN SQQUATTING.

8306C Parkin, M. WHAT CAN MACROECONOMIC THEORY TELL US ABOUT THE WAY DEFICITS
SHOULD BE MEASURED.

8307C Parkin, M. THE INFLATION DEBATE: AN ATTEMPT TO CLEAR THE AIR.

8308C Wooton, I. LABOUR MIGRATION IN A MODEL OF NORTH-SOUTH TRADE. 8309C Deardorff, A.V. THE DIRECTIONS OF DEVELOPING COUNTRIES TRADE: EXAMPLES
FROM PURE THEORY. 8310C Manning, R. ADVANTAGEOUS REALLOCATIONS AND MULTIPLE EQUILIBRIA: RESULTS
FOR THE THREE-AGENT TRANSFER PROBLEM. 
8311C DSU Mohammad, S. and Whalley, J. CONTROLS AND THE INTERSECTORAL TERMS OF TRADE IN INDIA.

8312C Brecher, Richard A, and Choudhri, Ehsan U. NEW PRODUCTS AND THE FACTOR CONTENT OF INTERNATIONAL TRADE.

$8313 \mathrm{C}$ Jones, R.W., Neary, J.P. and Ruane, F.P. TWO-WAY CAPITAL FLOWS: CROSSHAULING IN A MDDEL OF FOREIGN INVESTMENT.

$8314 C$ DSU Follain, J.R. Jr. and Jimenez, E. THE DEMAND FOR HOUSING CHARACTERISTICS IN DEVELOPING COUNTRIES.

8315C Shoven, J.B. and Whalley, J. APPLIED GENERAL EQUILIBRIUM MODELS OF TAXATION AND INTERNATIONAL TRADE.

8316C Boothe, Paul and Longworth David. SOME IRREGULAR REGULARITIES IN THE CANADIAN/U.S. EXCHANGE MARKET.

8317C Hamilton, Bob and Whalley, John. BORDER TAX ADJUSTMENTS AND U.S. TRADE.

8318C Neary, J. Peter, and Schweinberger, Albert G. FACTOR CONTENT FUNCTIONS AND THE THEORY OF INTERNATIONAL TRADE.

8319C Veall, Michael R. THE EXPENDITURE TAX AND PROGRESSIVITY.

8320C Melvin, James R. DOMESTIC EXCHANGE, TRANSPORTATION COSTS AND INTERNATIONAL TRADE.

8321C Hamilton, Bob and Whalley, John. GEOGRAPHICALLY DISCRIMINATORY TRADE ARRANGEMENTS.

8322C Bale, Harvey Jr. INVESTMENT FRICTIONS AND OPPORTUNITIES IN B ILATERAL U.S.-CANADIAN TRADE RELATIONS.

$8323 \mathrm{C}$ Wonnacott, R.J. CANADA-U.S. ECONOMIC RELATIONS-A CANADIAN VIEW.

8324C Stern, Robert M. U.S.-CANADIAN TRADE AND INVESTMENT FRICTIONS: THE U.S: VIEW.

8325C Harrison, Glenn, H. and Kimbell, Larry, J. HOW ROBUST IS NUMERICAL GENERAL EQUIL IBRIUM ANALYSIS?

8326C Wonnacott, R.J. THE TASK FORCE PROPOSAL ON AUTO CONTENT: WOULD THIS SIMPLY EXTEND THE AUTO PACT, OR PUT IT AT SERIOUS RISK?

8327C Bradford, James C. CANADIAN DEFENCE TRADE WITH THE U.S. Conklin, David. SUBSIDY PACTS.

Rugman, Alan M. THE BEHAVIOUR OF U.S. SUBSIDARIES IN CANADA: IMPLICATIONS FOR TRADE AND INVESTMENTS. 


\section{$\underline{1983}$}

8328d Boyer, Kenneth D. U.S.-CANADIAN TRANSPORTATION ISSUES.

8329C Bird, Richard M. and Brean, Donald J.S. CANADA-U.S. TAX RELATIONS : ISSUES AND PERSPECTIVES.

8330C Moroz, Andrew R. CANADA-UNITED STATES AUTOMOTIVE TRADE AND TRADE POLICY ISSUES.

8331C Grey, Rodney de C. and Curtis, John. INSTITUTIONAL ARRANGEMENTS FOR U.S.-CANADIAN NEGOTIATIONS. PART I: CANADA-U.S. TRADE AND ECONOMIC ISSUES: DO WE NEED A NEW INSTITUTION? PART II: INSTITUTIONAL ARRANGEMENTS FOR MANAGING THE CANADA-U.S. ECONOMIC RELATIONSHIP.

\section{4}

8401C Harrison, Glenn $W$. and Manning, Richard. BEST APPROXIMATE AGGREGATION OF INPUT-OUTPUT SYSTEMS.

8402C Parkin, Michael. CORE INFLATION: A REVIEW ESSAY.

8403C Blomqvist, Ảke, and McMahon, Gary. SIMULATING COMMERICAL POLICY IN A SMALL, OPEN DUAL ECONOMY WITH URBAN UNEMPLOYMENT: A GENERAL EQUILIBRIUM APPROACH.

8404C Wonnacott, Ronald. THE THEORY OF TRADE DISCRIMINATION: THE MIRROR IMAGE OF VINERIAN PREFERENCE THEORY?

8405C Whalley, John. IMPACTS OF A 50\% TARIFF REDUCTION IN AN EIGHT-REGION GLOBAL TRADE MODEL.

8406C Harrison, Glenn W. A GENERAL EQUILIBRIUM ANALYSIS OF TARIFr REDUCTIONS.

8407C Horstmann, Ignatius and Markusen, James R. STRATEGIC INVESTMENTS AND THE DEVELOPMENT OF MULTINATIONALS.

8408C Gregory, Allan W. and McCurdy, Thomas H. TESTING THE UNBIASEDNESS HYPOTHESIS IN THE FORWARD FOREIGN EXCHANGE MARKET: A SPECIFICATION ANALYSIS.

8409C Jones, Ronald $\mathrm{H}$. and Kierzkowski, Henryk. NEIGHBORHOOD PRODUCTION STRUCTURES WITH APPLICATIONS TO THE THEORY OF INTERNATIONAL TRADE.

8410C Weller, Paul and Yano, Makoto. THE ROLE OF FUTURES MARKETS IN INTERNATIONAL TRADE: A GENERAL EOUILIBRIUM APPROACH.

8411C Brecher, Richard A. and Bhagwati, Jagdish N. VOLUNTARY EXPORT RESTRICTIONS VERSUS IMPORT RESTRICTIONS: A WELFARE-THEORETIC COMPARISON. 
8412C Ethier, Wilfred J. ILLEGAL IMMIGRATION.

8413C Eaton, Jonathon and Gene M. Grossman. OPTIMAL TRADE AND INDUSTRIAL POLICY UNDER OLIGOPOLY.

$8414 \mathrm{C}$ Wooton, Ian. PREFERENTIAL TRADING AGREEMENTS - A 3xn MODEL.

8415C Parkin, Michael. DISCRIMINATING BETWEEN KEYNESIAN AND CLASSICAL THEORIES OF THE BUSINESS CYCLE? JAPAN 1967-1982

8416C Deardorff, Alan V. FIRless FIRwoes: HOW PREFERENCES CAN INTERFERE WITH THE THEOREMS OF INTERNATIONAL TRADE.

8417C Greenwood, Jeremy. NONTRADED GOODS, THE TRADE BALANCE, AND THE BALANCE OF PAYNENTS.

8418C Blomqvist, Ake and Sharif Mohammad. CONTROLS, CORRUPTION, AND COMPETITIVE RENT-SEEKING IN LDCs.

8419C Grossman, Herschel I. POLICY, RATIONAL EXPECTATIONS, AND POSITIVE ECONOMIC ANALYSIS.

8420C Garber, Peter M. and Robert G. King. DEEP STRUCTURAL EXCAVATION? A CRITIOUE OF EULER EQUATION METHODS.

8421C Barro, Robert J. THE BEHAVIOR OF U.S. DEFICITS.

8422C Persson, Torsten and Lars E.0. Svensson. INTERNATIONAL BORROWING AND TIME-CONSISTENT FISCAL POLICY.

8423C Obstfeld Maurice. CAPITAL CONTROLS, THE DUAL EXCHANGE RATE, AND DEVALUATION.

8424C Kuhn, Peter. UNION PRODUCTIVITY EFFECTS AND ECONOMIC EFFICIENCY.

8425C Hamilton, Bob and John Whalley. TAX TREATMENT OF HOUSING IN A DYNAMIC SEQUENCED GENERAL EỌUILIBRIUM MODEL.

8426C Hamilton, Bob, Sharif Mohammad, and John Whalley. RENT SEEKING AND THE NORTH-SOUTH TERMS OF TRADE.

8427C Adams, Charles and Jeremy Greenwood. DUAL EXCHANGE RATE SYSTEMS AND CAPITAL CONTROLS: AN INVESTIGATION.

8428 Loh, Choon Cheong and Michael R. Veall. A NOTE ON SOCIAL SECURITY AND PRIVATE SAVINGS IN SINGAPORE.

8429 Whalley, John. REGRESSION OR PROGRESSION: THE TAYING OUESTION OF INCIDENCE ANALYSIS.

8430 Kuhn, Peter. WAGES, EFFORT, AND INCENTIVE-COMPATIBILITY IN LIFE-CYCLE EMPLOYMENT CONTRACTS. 
8431 Greenwood, Jeremy and Kent P. Kimbrough. AN INVESTIGATION IN THE THEORY OF FOREIGN EXCHANGE CONTROLS.

8432 Greenwood, Jeremy and Kent P. Kimbrough. CAPITAL CONTROLS AND THE INTERNATIONAL TRANSMISSION OF FISCAL POLICY.

8433 Nguyen, Trien Trien and John Whalley. EOUILIBRIUM UNDER PRICE CONTROLS WITH ENDOGENOUS TRANSACTIONS COSTS.

8434 Adams, Charles and Russell S. Boyer. EFFICIENCY AND A SIMPLE MODEL OF EXCHANGE RATE DETERMINATION.

8435 Kuhn, Peter. UNIONS, ENTREPRENEURSHIP, AND EFFICIENCY.

8436 Hercowitz, Zvi and Efraim Sadka. ON OPTIMAL CURRENCY. SUBSTITUTION POLICY AND PUBLIC PINANCE.

8437 Lenjosek, Gordon and John whalley , POLICY EVALUATION IN A SMALL OPEN PRICE TAKING ECONOMY: CANADIAN ENERGY POLICIES. 